\title{
Corpos (Não) Controlados: Efeitos dos Discursos sobre Sexualidades em uma Escola Médica Brasileira
}

\section{(Un)Controlled Bodies: Effects of Discourses on Sexualities in a Brazilian Medical School}

\section{PALAVRAS-CHAVE}

- Educação Médica.

- Gênero e Sexualidade.

- HIV/aids.

- Autoetnografia performática.

- Estudos Culturais.
Gustavo Antonio Raimondi,III Flávia do Bonsucesso Teixeira ${ }^{I}$ Cláudio MoreiraII Nelson Filice de Barros ${ }^{\text {III }}$

\section{RESUMO}

As conquistas dos movimentos de lésbicas, gays, bissexuais, travestis e transexuais (LGBT) estabeleceram uma tensão na sociedade que sugere serem irreversíveis suas conquistas, inclusive em termos de visibilidade e recusa ao silenciamento. O cenário de redemocratização e a luta contra o preconceito e a discriminação, assim como pelos direitos humanos e acesso à saúde para todos, compõem alguns dos objetivos desses movimentos. Entretanto, a ideia ainda recorrente da impureza da homossexualidade, que posiciona o sujeito gay como "ser perigoso" reatualiza o estigma e a discriminação com base na suposta "contaminação presumida" do HIV/aids. Nesse sentido, o presente artigo tem por objetivo analisar os efeitos dos discursos sobre as (homo)sexualidades e o HIV/aids na formação médica. Por meio da autoetnografia performática, foi desenvolvida uma análise nas intersecções do self nos coletivos, do eu nas culturas, do agente nas agências, a partir de cenas (auto)etnográficas e da observação participante nos vários cenários de ensino-aprendizagem de uma escola médica pública brasileira. Observamos que, embora proscrito desde a CID 10, o diagnóstico de "homossexualismo" segue sendo produzido e produzindo efeitos por meio da solicitação sistemática e sem evidências de investigação do HIV/aids na formação médica. Assim, compreendemos que ainda há certa cultura hegemônica heterossexual-homofóbica na formação e no cuidado em saúde que atualiza o circuito da exclusão, dominação, colonização e subjugação do sujeito homossexual pela reiterada relação "ser gay - ter HIV/aids". Com os encontros e as experiências vividas aqui analisadas, explicitam-se visceralmente as disputas e os enfrentamentos no currículo, na esfera do cotidiano e em nossa própria consciência e prática diária para a produção de espaços que considerem outras possibilidades de existência para além da somente hegemônica heterossexualidade branca masculina. Concluímos, também, que foram e ainda continuam sendo abertas várias disputas na formação e atuação médicas, evidenciando que "não estamos sozinhos". Muitos(as) de nós estamos comprometidos(as) com a tentativa de construir outros modos de ensinar e cuidar, guiados por performances - escritas e corporificadas - de inclusão e resistência, cujo objetivo é expor, desafiar e transformar narrativas desumanas contra a população LGBT e a opressão em geral.

Universidade Federal de Uberlândia, Uberlândia, Minas Gerais, Brasil.

"Iniversity of Massachusetts Amherst, Amherst, United States.

III Universidade Estadual de Campinas, Campinas, São Paulo, Brasil. 


\section{KEY-WORDS}

- Medical Education.

- Gender and Sexuality.

- HIV/aids.

- Performance Autoethnography.

- Cultural Studies.

Recebido em: 13/12/18

Aceito em: 20/01/19

The achievements of the lesbian, gay, bisexual, transvestite and transsexual (LGBT) movements have established a tension in society that suggests that their accomplishments are irreversible, including in terms of visibility and refusal to remain silent. The scenario of re-democratization and the fight against prejudice and discrimination, as well as human rights and access to health for all, make up some of the objectives of these movements. However, the persistently recurrent idea of the dirtiness of homosexuality that positions the gay subject as being dangerous, reaffirm the stigma and discrimination from the alleged "presumed contamination" of HIV/aids. In this sense, this article aims to analyze the effects of discourses on (homo)sexualities and HIV/aids in Medical Education. By means of performative autoethnography, an analysis was performed at the intersections of the "self" in the collective, the self in the cultures, from (auto)ethnographic scenes and participant observation in the various teaching scenarios of a Brazilian public Medical School. We observed that, although proscribed since ICD 10, the diagnosis of "homosexualism" continues to be produced through the systematic and unproven application of HIV/aids research in medical education. Thus, we understand that there is still a certain heterosexualhomophobic hegemonic culture in health education and health care that updates the circuit of exclusion, domination, colonization and subjugation of the homosexual subject by the repeated relationship between "being gay - having HIV/aids". With the encounters and experiences that have been analyzed here, the disputes and confrontations in the curriculum, in the daily life and in our own daily consciousness and practice for the production of spaces that consider other ways of living beyond just hegemonic male white heterosexuality are made viscerally explicit. We also conclude that several disputes have been and are still being opened in medical training and performance, proving that "we are not alone". Many of us are committed to the attempt to construct other ways of teaching and caring, guided by performances - written and embodied - of inclusion and resistance, whose goal is to expose, challenge and transform dehumanizing narratives against the LGBT population and oppression in general.

\section{INTRODUÇÃO}

Quando falam desses corpos

Esses corpos que não importam

Que jazem jogados, abandonados no cemitério do silenciamento

Falam também do meu corpo

Afinal, minha posição profissional e social não altera

Esse que me dá vida, movimento

Que me faz acreditar e lutar por um mundo melhor

Quando não falam desses corpos

Se esquecem também de mim

Eu que aqui estou vivo, com sangue correndo nas veias

Se o meu sangue também corre

$O$ deles também corre

dando vida, cor, energia e esperança

E ainda acham que esse sangue está contaminado apenas por existir Sem perceber as vidas que pulsam em cada existência única
Como isso me atravessa?

Como isso me encontra?

Como isso me (re)produz no palco da minha vida?

Entro em cena, fecho as cortinas

Aplausos, vaias

Em quantos atos cabe a minha vida?

(Caderno de campo, abril de 2017)

As conquistas dos movimentos de lésbicas, gays, bissexuais, travestis e transexuais (LGBT) estabeleceram uma tensão na sociedade que sugere serem irreversíveis suas conquistas, inclusive em termos de visibilidade e recusa ao silenciamento ${ }^{1}$. No entanto, essa relação com a "saída do armário" enfrenta disputas em diferentes campos, e pode-se observar uma sistemática tentativa de dominação, exclusão e apagamento das experiências dos corpos "dissidentes", "divergentes", "desviantes", nos discursos de familiares, religiosos, estatais e acadêmicos. 
No Brasil, a necessidade do enfrentamento da epidemia do HIV/aids no início dos anos 1980 produziu o reconhecimento e a vocalização de determinadas demandas em saúde de grupos até então silenciados e invisibilizados, articulando diferentes sujeitos na academia, nas esferas de gestão e nos movimentos sociais ${ }^{2}$. O cenário de redemocratização e a luta contra o preconceito e a discriminação, assim como pelos direitos humanos e acesso à saúde para todos(as), compunham concomitantemente a luta por acesso universal aos medicamentos antirretrovirais e a participação popular como fundamental para organizar o cuidado, baseadas em outro modo de conceber o processo saúde-adoecimento-cuidado ${ }^{3}$.

No entanto, o reconhecimento de que foram implementadas estratégias exitosas de enfrentamento da epidemia exige também uma reflexão sobre as barreiras, as contradições e as descontinuidades. Ao tomar como exemplo a ambígua posição do Ministério da Saúde sobre a doação de sangue para as pessoas homossexuais, Seffner e Parker ${ }^{3}$ retomam um argumento que se tornou fundamental para o recorte proposto neste artigo: a ideia, ainda recorrente, da impureza da homossexualidade, que posiciona o sujeito gay como ser abjeto, indesejado, desprezível e perigoso, reatualizando o estigma e a discriminação com base na suposta "contaminação" do HIV/aids.

Se o estigma e a discriminação ainda seguem considerados desafios para o "viver" em tempos contemporâneos, em relação ao $\mathrm{HIV}$ /aids as homossexualidades permanecem produzindo tensões até mesmo em terrenos que pareciam menos arenosos, mais estáveis, como o do estabelecimento das normas. Ainda que a homossexualidade não seja enquadrada como doença desde a décima edição da Classificação Estatística Internacional de Doenças e Problemas Relacionados com a Saúde (CID), pesquisadores(as) demonstram que as condutas médicas seguem demarcando-a como transtorno. São recorrentes os momentos em que médicos e médicas deslocam a homossexualidade de um "diagnóstico previsto" na CID para um lugar de condição indesejada, origem/destino ou causa de sofrimento ${ }^{4-6}$.

No Brasil, a questão parece não estar resolvida nem mesmo no plano normativo quando a Resolução do Conselho Federal de Psicologia CFP 01/99 é objeto de disputa a cada momento de recrudescimento dos retrocessos quando se busca a chamada "cura gay"7. Exemplos podem ser observados nas situações em que profissionais recorreram à CID-9 (nos anos 2000) para apoiar o uso do termo "homossexualismo", já suspenso à época².

Desta forma, encontramos nos cenários de ensino-aprendizagem das profissões em saúde, em especial na escola médica, discursos apoiados na percepção do HIV/aids como punição moral e outros discursos que, com diferentes recursos, aprisionam a homossexualidade como doença ou desvio (resultante também de um juízo moral). Nesse jogo de deslocamentos, onde ora a homossexualidade é a própria doença, ora ela "causa" doenças (incluindo o HIV/aids), os discursos seguem ainda pouco problematizados na literatura indexada da área da saúde, (re)produzindo invisibilidades, iniquidades e injustiças sociais. Assim, o objetivo deste artigo é analisar, por meio de uma autoetnografia performática, os efeitos dos discursos sobre as (homo)sexualidades e o HIV/aids na formação médica.

\section{PERCURSO METODOLÓGICO}

Atravesso por entre esses corredores

Aqui me formei médico, aqui me descobri gay

Aqui vivi o amor, o medo, a dúvida da descoberta de mim mesmo

Hoje sou atravessado por esses corredores

Repletos de pessoas, cartazes, histórias e dizeres

Que dizem que eu não deveria estar aqui

Pelo menos não gay

Como seguir em frente caminhando

Se a mata densa do preconceito

É capaz de fechar os olhos daqueles que não querem me ver gay?

E se eu, que surgi daqui, não sou visto se me assumo gay

Como ver outros gays que estão para além desses corredores?

(Caderno de campo, agosto de 2016)

Por meio de cenas (auto)etnográficas vividas durante o período de observação participante numa escola de Medicina de uma instituição pública brasileira, foi desenvolvida uma autoetnografia performática, que tem sido usada nas investigações de experiências vividas nas intersecções do self nos coletivos, do eu nas culturas, do agente nas agências. Ela requalifica a relação entre objeto e observador, reposicionando a interação e a experiência pessoal do pesquisador como forma de construção do conhecimento ${ }^{8-10}$. Diante disso, o percurso metodológico incluiu e considerou as impressões e reflexões vivenciadas pelo próprio pesquisador como estratégias de não silenciamento do corpo/mundo daquele que pesquisa.

Tendo por base a experiência de ser gay, branco, classe média, médico e docente, o primeiro autor produziu as possibilidades da performance ${ }^{10,11}$ do pesquisador. A narrativa aqui recontada não é a do "Outro" observado, perscrutado e 
analisado, nem tampouco do self do pesquisador, como uma reflexão psicanalítica, mas evocada nos sentimentos, pensamentos e práticas incorporados no autoetnógrafo. Trata-se dos encontros do "Outro" e do eu para além de localizações espaçotemporais fixas, reconhecendo o fluxo performático do "eu-e-o-Outro" e do "eu-como-o-Outro"12. Nessa perspectiva, pode-se ter uma ampliação do olhar etnográfico, pois membros de grupos marginalizados, e consequentemente relegados a posições de "objetos", se tornam explicitamente os produtores do conhecimento, que, por meio de uma complexidade crítica, desafiam e expõem as formas de opressões na e da experiência vivida e na e da construção acadêmica ${ }^{10-13}$. Com isso, permitem "examinar a justiça social, os sistemas de opressão e o neocolonialismo de nossos encontros com experiências vividas entre identidades e mundos"14 (p. 39).

As cenas recontadas neste artigo foram escolhidas por traduzirem a eficácia simbólica de elementos que insistem em manter atrelados a homossexualidade e o risco de infecção pelo vírus do HIV, carregando como lembrete os "perigos" dos sujeitos e das sexualidades "dissidentes", "divergentes", "desviantes". Serão relatadas neste artigo algumas cenas registradas no caderno de campo ${ }^{15}$ no período de agosto de 2016 a dezembro de 2017 nos diversos cenários de uma Faculdade de Medicina que me afetaram ${ }^{16}$ e passaram a compor a análise aqui desenvolvida. Vivi nesse espaço nos últimos dez anos como discente do curso de Medicina, profissional médico, discente da pós-graduação, residente em Medicina de Família e Comunidade, docente do curso de Medicina e pesquisador.

Em relação às questões éticas, o presente projeto seguiu as orientações presentes na Resolução $n^{\circ} 510$, de 7 de abril de 2016, sendo aprovado pelo Comitê de Ética em Pesquisa com Seres Humanos, sob o Parecer $n^{\circ} 1.776 .686$ e CAAE:57578116.0.0000.5152.

\section{CONTEXTO, CENAS, DISCUSSÕES E REFLEXÕES}

Encontro-me novamente com essa escola

Agora não mais estudante

Médico

Professor

Pesquisador

Porém meu corpo é o mesmo

Será que agora ele terá a oportunidade de existir?

O currículo mudou

Uma chance para uma nova história

Ou um atalho para o passado?
Até quando tanto silêncio?

Até quando tanta dor?

Até quando resistir?

Chorar

Sorrir

Existir

Será que isso basta?

(Caderno de campo, abril de 2016)

\section{Atravessamentos profissionais no "ser gay"}

Em 2015 me tornei docente do curso de Medicina. Não somente me descobria em um novo lugar, mas essa travessia se dava num cenário também novo, em que a mudança curricular provocava disputas, alegrias, certezas e inseguranças. Entre as frestas abertas, um espaço para pautar as questões de gênero e sexualidade no cuidado em saúde, em um currículo em fase de implementação.

Durante a graduação, os escritos de Krafft-Ebing do século XIX, em seu livro Psychopathia Sexualis ${ }^{17}$, se materializavam em meu corpo, que era assim marcado pela "(psico)patologia" do desejo e do afeto "desviante" - exemplificando, dessa forma, a scientia sexualis de controle e dominação dos corpos pelo sujeito homem-branco-heterossexual, proposta por Foucault ${ }^{18}$. Percebia em minha própria existência os mecanismos disciplinadores pautados na degenerescência ${ }^{4}$, ou seja, no afastamento da "condição ideal" para um corpo com um pênis. "Deveria ser heterossexual para garantir a procriação de uma espécie, certo?!". Dessa forma, os discursos médico-científicos geravam minha exclusão, minha abjeção, minha subjugação.

Para mim e talvez para outros gays como eu, somente havia a possibilidade de reconhecimento para a prática médica dentro da condição onde somente me resta(va) a posição de...

Doença-entidade ${ }^{19}$
Patologia
Vetor
Grupo de risco

Doente Marginal

Desviante

Outro.

Mas, para uma posição de sujeito "legítimo" em pesquisa, em sala de aula e consultório médico, deveria performar um corpo heterossexual, branco, classe média? Como um estu- 
dante heterossexual não me veria como um "risco"? Deveria negar o "armário" em que aprendi a estar? Mas como aprendi dentro desse "armário" a ficar? Potentes trancas aprendi a colocar nesse armário para minha sexualidade ali aprisionar e, quem sabe, garantir o "espaço legítimo" para minha existência vivenciar. Parecia-me que somente após as "fronteiras" do "legítimo", no escuro do desconhecido, no lugar possível da inexistência, poderia experimentar e vivenciar as potências de meu corpo.

Infelizmente, a materialização da condição de comportamento de risco, de culpabilização do desejo "não contido" e "não protegido", era elucidada e exemplificada sistematicamente durante as disciplinas que tratavam do tema HIV / aids. O discurso do desvio, da doença, do "ser gay - ter HIV/aids" foi sistematicamente articulado por professores(as), em diferentes disciplinas e cenários de ensino-aprendizagem, onde eu e meus/minhas colegas aprendemos a fazer essa relação inexorável, disfarçada de "evidência epidemiológica" relacionada ao então chamado "grupo de risco". Mas onde estavam os(as) outros(as) professores(as) que não concordavam com isso? Estariam na periferia do "legítimo", tentando com gritos sufocados se fazerem ouvidos(as)?

Um dos efeitos dessa "condição de comportamento de risco" era o medo. Minha imaturidade alimentava o medo de ser reconhecido como "agente poluidor". Medo que fragilizava e envolvia toda a minha potência de vida na possibilidade de infecção pelo vírus HIV apenas por ser gay, pois o que ouvia nos corredores da instituição eram falas de que ter/viver com $\mathrm{HIV} /$ aids estava atrelado intimamente ao comportamento "arriscado", "pervertido", "desviante", "inadequado", "errado" e "estranho" "desses pacientes". Não percebia que estava tomado também pela produção discursiva de que viver com $\mathrm{HIV}$ / aids é ruim, não percebendo as potências de vidas que existem para além de diagnósticos e estigmas.

No entanto, em vários momentos de atendimentos a outros gays, eu reproduzi essa relação por meio da prescrição da investigação do HIV/aids, mesmo diante da ausência de evidências clínicas para solicitar tal exame, reforçando o testar/tratar como modelo único para a prevenção e combate ao $\mathrm{HIV} /$ aids $^{20}$. Até mesmo comigo, sem uma vida sexual ativa, insistia em submeter-me à sorologia e receber o resultado negativo em um ritual que mesclava o alívio com a incredulidade. Essa perversão discursiva colonizou, dominou o meu modo de cuidar. Seduzido pela suposta coerência dos saberes que "detinham as certezas", a "ciência", a "legitimidade", acabei, também, não reconhecendo minha corporalidade gay no espaço do cuidado. Violentei-me e fui violentado à redução, ao silenciamento, à exclusão, à inexistência, para me manter supostamente "legítimo" num ambiente que me parecia aureolado pela "perfeição", "pureza", "comportamento correto", "ausência de doenças e desvios". Mesmo com a nova proposta curricular, as questões de gênero e sexualidade se apresentavam prioritariamente relacionadas aos temas da reprodução e do adoecimento.

\section{Presságios (im)...possíveis}

Chegando para iniciar uma tarde de encontros com os(as) estudantes do componente curricular coordenado por mim, fui surpreendido com a imagem de um estudante com olhos aflitos e cabisbaixo que vinha em minha direção. Entre expressões que indicavam revolta e incredulidade, ele andava pelo corredor de uma forma enérgica, agitada, com os pés firmes no chão e a cabeça fazendo um movimento rítmico cuidadosamente orquestrado, como que a reproduzir a movimentação mecânica de um pêndulo, que oscilava indicando uma não aceitação de algo que até então eu não poderia supor o que seria.

Sabia que, naquele momento do curso de Medicina, esse estudante estava em um período caracterizado pelo início do aprimoramento do chamado "raciocínio clínico". Por meio de várias unidades curriculares, os "problemas" apresentados pelos(as) "pacientes" eram articulados com os dados coletados durante a entrevista médica e o exame físico do corpo, para serem traduzidos em hipótese(s) de problema(s) ou diagnóstico(s). Para treinar isso, os(as) estudantes participavam de pequenos grupos de discussões de "casos simulados" sob a orientação de um(a) professor(a). Nesse período, o "cenário biológico" dos "casos" apresentados ao ensino-aprendizagem estava relacionado com as doenças infecto-parasitárias, nas quais vírus, bactérias e fungos interagiam com o corpo, desencadeando sinais e sintomas que eram decodificados em "hipóteses diagnósticas".

Comecei a refletir sobre o que poderia estar acontecendo naquele momento, mas não conseguia antecipar. Olhando para o estudante, me vi em seus olhos. Como um estudante aflito em um passado de mais de sete anos atrás, algo me guiava para várias posições de reconhecimentos com aquele "eu-estudante", "eu-como-o-estudante". Tive medo, mas precisava me aproximar. A cada passo que dava em direção ao estudante, meu coração batia mais rápido e mais forte.

Tun tá

Tun.........tá

Tun......tá

Tun....tá

Tun.tá

Tuntá 
Tutá

Ttá

Tá

Tão rápido e tão forte que não consegui ouvir o que se passava ao redor e, muito menos, os meus pensamentos. Por alguns passos senti o silêncio da fala, o silêncio dos pensamentos, o silêncio da memória e percebi a voz do meu corpo. Em um turbilhão de sentimentos e sensações meu corpo falava, gritava aterrorizado pela possibilidade de o sofrimento daquele estudante estar relacionado à sua orientação afetivo-sexual. Temia que, ao encontrá-lo, reconheceria que, no limite, minha existência ali também não deveria ou não poderia existir.

\section{Um passado(?)... "problemático"(?)}

Nos encontramos. Estávamos sozinhos, somente as paredes do corredor cinza da instituição seriam testemunhas desse encontro. Por um breve momento, o que percebi era, novamente, o meu coração gritando aceleradamente, mas agora somado à escuta do coração acelerado e angustiado do estudante. Talvez a emoção daquele momento não me permita relembrar com exatidão as palavras produzidas por ele. Ao reproduzir seu relato, mantenho a ideia, o conteúdo, sem o apego à exatidão dos termos utilizados, corporificando e recriando um passado não como uma sucessão linear de eventos ou de fatos, mas como uma série de histórias, narrativas, emoções e sensações que explicitam momentos de opressão, de perigo, de violência, de não existência ${ }^{21}$.

De repente, como uma torrente, ouvi o relato expresso por uma voz aterrorizada, indignada, sofrida:

E o PROFESSOR disse que era pra gente colocar como hipótese diagnóstica HIV/aids porque o paciente era GAY!

Ouvi.

Não ouvi o que queria ouvir

Ouvi o que precisava ser ouvido.

Ouvi o outro e acabei me ouvindo.

Mas não queria me ouvir.

Não queria ouvir isso.

Não queria reviver isso.

Por alguns instantes, não soube o que responder, o que fazer e o que dizer. Apenas fiquei em estado de choque e, como o estudante, fiquei aterrorizado, indignado, sofrido. Por alguns segundos me perguntei por que o estudante havia me contado isso. Seria eu o primeiro professor a passar por aquele corredor logo após o ocorrido? Mas e se fosse outro(a) professor(a) que o tivesse encontrado, ele também teria contado? E se ele não soubesse que eu sou gay, será que ele teria ainda assim me contado ou teria se calado, como eu muitas vezes fiz?

Reli com o estudante o "caso-problema" apresentado. Nada na história apresentada seria evidência clínica para solicitar tal exame. Nenhum indício unicamente clínico que justificasse a possibilidade diagnóstica do HIV/aids. Nada além do fato do suposto "paciente" ser um homem gay. Como num flashback, me recordei de outros momentos vividos com outros estudantes gays e como um estudante gay.

Recordei, imediatamente, o encontro com uma estudante lésbica de outra época, que aos prantos e com punhos cerrados da raiva contida pelo medo de se expressar, me dizia que seu professor branco, heterossexual, de Clínica Cirúrgica disse a ela e a seus colegas - um grupo de aproximadamente dez estudantes, com cinco gays e uma lésbica - que era para terem cuidado com os chamados acidentes biológicos. Isto porque, se "pegassem" HIV/aids, até que "provassem" o contrário, sofreriam o estigma de serem considerados homossexuais, pois HIV/aids é "coisa de viado". Com isso, o professor expressava, também, sua preocupação em manter a imagem de pureza relacionada ao "ser médico", na qual somente o outro "contaminaria" "o médico", somente o outro "poderia" ser gay e somente o gay "teria" HIV / aids e que isso era inevitavelmente ruim. Mas será que somente "o médico" estaria sob a "ameaça" de "contaminação"? E o que essa "ameaça" ameaça? E, ainda, será que "o médico" não poderia ser gay, vivendo com ou sem o HIV/aids?

Em uma memória de outrora, que invadiu com violência minha mente, recordei-me de um encontro com um grupo de estudantes que organizavam um simpósio sobre saúde LGBT. Em um grupo diverso de identidades de gêneros, orientações afetivo-sexuais, raças/etnicidades e classes sociais, uma estudante contou, decepcionada, que durante uma prova teórico-prática, aplicada por uma professora branca e heterossexual do curso de Clínica Médica, era esperado que ela e seus colegas solicitassem investigação do HIV/aids, pois o caso em questão era de um adulto jovem, de 24 anos, sem queixas, sem alterações ao "exame físico", em busca de "exames de rotina", "porém" homossexual. Ao apontar para a professora um possível preconceito pela falta de evidências clínicas que justificassem aquela solicitação, a estudante ouviu que "não tinha nada disso", pois ela, a professora, somente estava "ensinando" a "atentarem para um risco".

Um misto de sentimentos reverberava o passado, quando em vários momentos estive posicionado como um risco, um perigo e até como um perigoso "vetor" do HIV/aids. Era difícil acreditar que o passado performava o presente, agora revivido por outros(as) estudantes, gays ou não. Recordei-me também que em uma "corrida de leitos" eu e meus colegas nos 
deparamos com um quadro na enfermaria hospitalar que descrevia brevemente a suspeita clínica dos "pacientes" internados. Entre várias descrições dos casos, uma médica residente, ao ser questionada sobre a suspeita de HIV / aids em relação a uma das pessoas internadas, afirmou que repetia a hipótese de seu colega residente que tinha apontado essa suspeita com base no fato de que o "paciente" "só poderia ser gay", uma vez que era um homem jovem e tinha um quadro infeccioso associado. Achando um pouco estranho, o preceptor questionou se o "paciente" tinha "história" de relacionamentos homoafetivos. A residente contou então que, como seu colega médico residente, tinha observado que esse "paciente" usava uma aliança de prata na mão esquerda e "só os gays" usam essas alianças na mão esquerda, já que não "podiam" usar uma "de verdade", de ouro. Diante da resposta, o preceptor (homem, branco e heterossexual) concordou e afirmou que de fato "teriam que suspeitar mesmo".

Ao anunciar o sujeito como gay supostamente, esses(as) professores(as) autorizariam médicos e médicas em formação a decidirem pela prescrição da investigação do HIV / aids. Não se trata de uma conduta qualquer. Essa prática mantém o sujeito enredado na tênue linha entre os estereótipos fixados de ser "desacreditável", em que a característica estigmatizante não é imediatamente perceptível, e "desacreditado", em que a característica estigmatizante é imediatamente perceptível ${ }^{22}$. O marcador de diferença, ou seja, a orientação afetivo-sexual, foi aqui acionado ao longo dessas histórias não para se pensar como se interseccionaria com outros marcadores, mas no sentido de produzir estigmas ${ }^{22}$, produzir iniquidades em saúde ${ }^{23}$ para o sujeito.

Como uma "acusação", ser gay deveria, então, representar para mim e talvez para esses(as) estudantes e para esses(as) usuários(as) o conceito de "grupo de risco"24. Descontextualizada de outras evidências, a solicitação do exame deveria funcionar como um lembrete sobre o "perigo" da homossexualidade e suas "práticas desregradas". Nessa esteira de opressões, a formação médica permanece operando engrenagens que dificultam a "despatologização" da homossexualidade por meio da reiteração de certa cultura hegemônica heterossexual-homofóbica que reitera a presença do não lugar dos corpos gays ou, na verdade, reitera a presença do seu lugar marginal ou, ainda, a presença do seu lugar central quando associado ao HIV/aids.

Entretanto, é importante lembrar que:

[...] não há nada que seja uma presença transmitida mas antes uma represença, ou uma representação ${ }^{25}$ (p. 52).
Mas...

A linguagem preserva o corpo, mas não de maneira literal, trazendo-o à vida ou alimentando-o; ao contrário, traz uma certa existência social do corpo graças à sua interpelação em termos de linguagem. Para entender isso, é preciso imaginar uma situação impossível em que um corpo que ainda não recebeu uma definição social, um corpo que é, a rigor, inacessível torna-se acessivel no momento em que nos voltamos para ele com um chamado, uma denominação ou uma interpelação que não "revela" o corpo mas o constitui fundamentalmente ${ }^{26}$ (p. 21) [tradução dos autores].

Assim...

O corpo gay,

nessa enunciação de uma cultura hegemônica heterossexual-homofóbica,

é uma representação discursiva heterossexual constituindo o corpo-gay-na-visão-do-corpo-hétero, por isso a prescrição sistemática de investigação do $\mathrm{HIV}$ / aids

para os corpos gays,

independentemente da real "necessidade" clínica.

Ou... um presente(?)... "problemático"(?)

Em todas essas histórias, recordo-me de que a primeira abordagem foi de apagamento, ou seja, o impulso inicial foi me perguntar...

"mas será que o(a) professor(a) falou isso mesmo?

mas será que foi isso que ele(a) quis dizer?

mas será que não estamos exagerando?

mas será que o raciocínio clínico não comporta mesmo essa hipótese?

mas será ... ?"

Questionei internamente o relato dos(as) estudantes, abafei minha memória e meus sentimentos, como uma forma de amenizar o relato, negar o preconceito e reiterar, como em outras situações, o mito de que a homofobia não existe em meu contexto. Na universidade não... nos cenários de ensino-aprendizagem de um curso de Medicina não... Mas por que estava fazendo esse movimento? O que me convocava para continuar na invisibilidade e recrutar esses(as) estudantes para esse enquadramento?

$\mathrm{Eu}$, que passei toda a graduação parodiando, criando artificialmente uma heterossexualidade pautada em um suposto "modelo original de humano", deveria seguir a "ordem" da natureza e ser heterossexual ${ }^{27}$. Diferentemente de mim, os(as) estudantes não aceitaram negociar com o armário. De muitos modos eles me diziam: sou homem, gay/heterossexual e me 
recuso a responder a esse jogo enunciativo ${ }^{28}$. Elas, também, de muitos modos disseram: sou mulher, lésbica/heterossexual e me recuso a responder à naturalização da violência.

Esses(as) estudantes me convocaram. Reacenderam em meu corpo as dores que marcam um lugar de fala ${ }^{29}$, um lugar de existência do qual aparentemente não posso sair: o do abjeto $^{30}$, do indesejado, do desprezível, do perigoso, do subalterno, do excluído, do "outro". Compreendi nesse momento que o estigma do HIV/aids se manteve como uma peça fundamental para fazer girar as engrenagens dos dispositivos ${ }^{18}$ de controle das (homo)sexualidades, mesmo com "evidências científicas" insuficientes para manter amalgamados os termos gay-HIV/aids. A homofobia ${ }^{31}$ era/é, assim, atualizada em um circuito de exclusão, dominação, colonização e subjugação pela reiterada relação "ser gay - ter HIV / aids".

Ser homem,

Ser branco,

Ser classe média,

Ser médico,

Ser professor

Me posicionaria num espectro de privilégios em um dado lugar de fala ${ }^{29}$, compartilhado com os(as) professores(as) que disparam as cenas relatadas. Embora o perfil dos profissionais da medicina no Brasil esteja se modificando, a profissão ainda é predominantemente masculina ${ }^{32}$. Em relação à raça/cor/ etnia, não seria equivocado apontar a hegemonia das pessoas que se declaram brancas como integrantes da categoria ${ }^{32}$. Eu participava desse conjunto de privilégios até que a minha sexualidade produzisse o ponto "fora da curva". Neste lugar, eu seria o "problema"33. A minha homossexualidade seria o "problema". Eu me subjetivava como um "problema". E o HIV/aids estava ali. Um lembrete para "delimitar" a área de segurança, a linha que delimita a fronteira ${ }^{34}$ : "na medicina gay só adentra como problema".

Essa situação, negligenciada por mim e reiterada pela minha própria negligência a ela, apresentava-se a mim como um resultado da perversão social binária de um estereótipo SUPERIOR $^{35,36}$, de uma identidade SUPERIOR de homem, branco, heterossexual, classe média, frente aos sujeitos subalternos ${ }^{37}$. Assim, para ser "aceito" e "legitimado", deveria negar/esconder minha diferença e, consequentemente, abnegar minha individualidade e minha existência para-si, para reafirmar a minha existência para-o-outro? Nessa perversão, identifiquei-me reproduzindo a lógica colonial ${ }^{38-40}$, pois não via como "pode o subalterno falar" ${ }^{\prime \prime}$. Mas...

Talvez até agora não tenhamos avaliado uma questão, a de que a marcação implica uma dor. [...] Mas para que o lugar da dor se torne lugar de fala, é preciso articular a dor, reconhecê-la, colocá-la em um lugar político, aquele lugar onde o outro está incluído como um sujeito de direitos que também tem a sua dor ${ }^{41}$ (p. 2).

Entretanto, o silêncio, a alienação e o apagamento foram anunciados para mim como estratégias "seguras" para a possibilidade da existência gay no curso de Medicina. O ocultamento e o suposto desconhecimento do "desvio", bem como a opressão de possibilidades não heterossexuais pareciam funcionar como lembretes de que transgredir a norma pode tornar a vida insuportável devido à existência na e pela negação. Percebi que a educação é frequentemente uma ferramenta para "justificar a iniquidade". No entanto, o que não tinha ainda percebido é que, em certa medida, a "alienação" desta forma de educação pode ser também considerada um "ato ativo de resistência"21 (p. 247).

\section{Ou... um futuro(?)... "problemático"(?)}

Esses encontros me deslocaram. Agora não era mais entre estudantes gays que viviam a clandestinidade "do amor que não ousa dizer seu nome"1 e construíam estratégias de sociabilidades possíveis no curso de Medicina. Como gay-professor, não podia/queria mais existir a partir do armário. Esses(as) estudantes me convocavam a um (re)posicionamento. Mas e se, além disso, eu fosse negro, fosse mulher, fosse pobre, não fosse médico, não fosse professor? E se o Outro fosse negro, fosse mulher, fosse pobre, não fosse estudante de Medicina? Que efeitos discursivos e intersubjetivos essa interação teria provocado? Que (re)posicionamentos teriam sido convocados? O que mais seria acionado/produzido nesse encontro eu-Outro/eu-como-o-Outro?

\section{CONSIDERAÇÕES... (FINAIS?)}

As linhas de fuga

Pareciam não se desenhar.

E, pior,

As condições para sua tessitura

Parecia não encontrar.

Estaria...

Sozinho!

Sozinho?

Não! 
Gritos emudecidos

Comecei a encontrar

Tornando o silêncio da dor

Um lugar transformador

Para juntos resistir

E jamais desistir!

De mamas, úteros e vaginas

De pênis e testículos

E de muitas outras partes mais

Muitos Outros corpos foram se constituindo.

Entre esperanças e solidariedade

Caminharemos adiante

Sem deixar nenhum(a) para trás.

(Caderno de campo, junho de 2017)

Por meio da valorização das experiências viscerais situadas nos corpos excluídos, propomos neste texto autoetnográfico uma coconstrução na performance eu-Outro/eu-como-o-Outro, ampliando, assim, o "círculo de inclusão na educação", que agrega mais e mais pessoas por meio de uma "ressonância visceral"21 (p. 247).

Com essas experiências pudemos reconhecer a medicina como uma instituição formada por pessoas que historicamente participam de construções de normas, que ora incluem ora excluem comportamentos, sujeitos, corpos. Com os encontros e as experiências vividas aqui analisados, explicitam-se visceralmente as disputas e os enfrentamentos no currículo, na esfera do cotidiano e em nossa própria consciência e prática diária para a produção de espaços que considerem outras possibilidades de existências para além da somente hegemônica heterossexualidade branca masculina.

As cenas aqui analisadas formam um "lembrete" de que as sexualidades não hegemônicas são ainda materializadas como questões para o saber médico quando relacionadas à noção de "desvio" dos códigos que a própria medicina contribuiu para normatizar ${ }^{42}$. O "diagnóstico" de "desvio", de "anormalidade", de "não coerência", de "não conformidade" com o pressuposto biológico-social está imbricado no pressuposto diagnóstico do HIV/aids para os corpos gays por meio da sistemática solicitação da investigação do HIV/aids, independentemente de um pressuposto clínico-epidemiológico.

Além disso, categorizar uma vida com HIV/aids como ruim e buscar associar essa suposta "tragédia de vida" à homossexualidade é uma tentativa de remeter o ser gay novamente à margem. Assim, o medo de um futuro de dor passa a atuar como dispositivo de controle dos corpos, que "devem buscar", a "qualquer custo", ser heterossexuais e "sãos". Dessa forma, pareço viver uma época onde a (des)informação produz preconceitos e violências que ainda hoje marcam diversos corpos gays, mesmo quando nós temos possibilidades de produzir novas construções e caminhos para um cuidado em saúde equânime e integral.

Abrimos, diantedetudoisso, uma disputa esabemos quenão estamos sozinhos(as). Muitos(as) de nós - até emudecidos(as), mas jamais em silêncio - estamos comprometidos(as) com a tentativa de construir diferentes modos de vida, guiados por performances - escritas e corporificadas - de inclusão e resistência, cujo objetivo é expor, desafiar e transformar narrativas desumanas contra a população LGBT e contra a opressão em geral. Dessa forma, muitos e muitas se somam, contribuindo com suas ferramentas e fios para tecermos juntos e juntas as linhas de fuga que redesenham outros modos de ensino e cuidado orientados pela inclusão da diferença e emancipação ${ }^{43}$, como por meio de uma pedagogia da esperança ${ }^{44}$ e da solidariedade ${ }^{45}$.

\section{REFERÊNCIAS}

1. Sedgwick EK. A epistemologia do armário. Cad PAGU. 2007;28:19-54.

2. Teixeria F do B. Dispositivos de dor: saberes-poderes que (com)formam as transexualidade. 2013.

3. Seffner F, Parker R. Desperdício da experiência e precarização da vida: momento político contemporâneo da resposta brasileira à AIDS. Interface-Comunicação, Saúde, Educ [Internet]. 2016;20(57):293-304.

4. Moscheta M dos S. Responsividade como recursos relacional para a qualificação da assistência à saúde de lésbicas, gays, bissexuais, travestis e transexuais. Universidade de São Paulo - Faculdade de Filosofia, Ciências e Letras; 2011.

5. Paulino DB. Discursos sobre o acesso e a qualidade da atenção integral à saúde da população LGBT entre médicos (as) da estratégia saúde da família [Internet]. Universidade Federal de Uberlândia; 2016.

6. Fébole D da S, Moscheta M dos S. A população lgbt e o sus: produção de violências no cuidado em saúde. In: V Simpósio Internacional em Educação Sexual - saberes/trans/versair currículos identitários epluralidade de hênero [Internet]. Maringá - PR; 2017. p. 1-13. Disponível em: <http:/ / www.sies.uem.br/trabalhos/2017/3164.pdf>.

7. Sposito SE. Desafios para a manutenção da despatologização das homossexualidades na psicologia brasileira. In: Rasera, E; Pereira, M; Galindo D, editor. Democracia Participativa, Estado e Laicidade: Psicologia Social e enfrentamentos em tempos de exceção. 1st ed. Porto Alegre: ABRASCO; 2017. p. 227-42. 
8. Ellis C, Adams TE, Bochner AP. Autoethnography: an overview. Hist Soc Res Sozialforsch [Internet]. 2011;36(4):27390.

9. Versiani DB. Autoetnografias: conceitos alternativos em construção. Rio de Janeiro - RJ: 7Letras; 2005.

10. Denzin N. Performance autoethnography - critical pedagogy and the politics pf culture. 2nd ed. New York - NY: Routledge, 2018.

11. Alexander BK. Performance ethnography: The reenacting and inciting of culture. In: The Sage handbook of qualitative research. Thousand Oaks - CA: Sage; 2005. p. 411-42.

12. Diversi M, Moreira C. Betweener autoethnographies - a path towards social justice. 2nd ed. New York - NY: Routledge, 2018.

13. Farrell L, Bourgeois-Law G, Regehr G, Ajjawi R. Autoethnography: introducing 'I'into medical education research. Med Educ [Internet]. 2015;49(10):974-82. Disponível em: <https:/ / onlinelibrary.wiley.com/doi/epdf/10.1111/ medu.12761>.

14. Diversi M, Moreira C. Autoethnography Manifesto. Int Rev Qual Res. 2017;10(1):39-43.

15. Malinowski B. Um diário no sentido estrito do termo. Rio de Janeiro - RJ: Record; 1997.

16. Siqueira P. "“Ser afetado", de Jeanne Favret-Saada". Cadernos de Campo (São Paulo, 1991) 13.13 (2005): 155-161.

17. Krafft-Ebing R Von. Psychopathia Sexualis - A Clinical-Forensic Study. Bloat Books; 1886.

18. Foucault M. História da sexualidade 1: a vontade de saber. 3rd ed. São Paulo: Paz e Terra; 2015.

19. Laplantine F. Antropologia da doença. 4th ed. São Paulo SP: Martins Fontes; 2010.

20. Reis V. Aids, é preciso assumir o fracasso da prevenção no Brasil. ABRASCO [internet]. 2018. Disponível em: <https:/ / www.abrasco.org.br/site/outras-noticias/saude-da-populacao/aids-e-preciso-assumir-o-fracasso-da-prevencao-no-brasil/34769/>.

21. Moreira C, Diversi M. Missing bodies: troubling the colonial landscape of American Academia. Text and Performance Quaterly. 2011;31(2):229-248.

22. Goffman E. Estigma: notas sobre a manipulação da identidade deteriorada. 4th ed. Rio de Janeiro - RJ: LTC; 1988.

23. Barata RB. Como e por que as desigualdades sociais fazem mal à saúde. Rio de Janeiro: Editora Fiocruz, 2009.

24. Ayres J., et al. O conceito de vulnerabilidaAde e as práticas de saúde: novas perspectivas e desafios. In: Czeresnia D, Freitas CM (Eds.). Promoção da saúde: conceitos, reflexões, tendências. 2. ed. Rio de Janeiro - RJ: Fiocruz, 2009. p. 121-44.
25. Said EW. Orientalismo: o Oriente como invenção do Ocidente. São Paulo - SP: Companhia das Letras; 2007.

26. Butler J. Lenguaje, poder e identidad. Madrid: SÍNTESIS; 2004.

27. Butler J. Problemas de gênero: feminismo e subversão da identidade. 11th ed. Rio de Janeiro: Civilização Brasileira; 2016.

28. Butler J. O clamor de Antígona: parentesco entre a vida e a morte. Florianópolis -SC: UFSC; 2014.

29. Ribeiro R. O que é lugar de fala? Belo Horizonte: Letramento, 2017.

30. Kristeva J. Poderes de la perversión. 5. ed. Coyoacan - Mexico: Siglo XXI, 2004

31. Borrillo D. Homofobia: história e crítica de um preconceito. Belo Horizonte - MG: Autentica; 2015.

32. Scheffer MC, et al. Demografia médica no Brasil 2018. São Paulo: Departamento de Medicina Preventiva da Faculdade de medicina da USP, Conselho Regional de Medicina do Estado de São Paulo, Concelho Federal de Medicina, 2018.

33. Canguilhem G. O normal e o patológico. 7th ed. Rio de Janeiro - RJ: Forense Universitária; 2015. Anzaldua G. Borderlands/La Frontera: The New Mestiza. 4th ed. San Francisco: Aunt Lute Books; 2012.

34. Anzaldua G. Borderlands/La Frontera: The New Mestiza. 4th ed. San Francisco: Aunt Lute Books; 2012.

35. Hall S. Cultura e representação. Rio de Janeiro - RJ: PUC-Rio : Apicuri; 2016.

36. Minh-Ha TT. Woman, Native, Other - Writing Postcoloniality and Feminism. Bloomington, IN: Indiana University Press; 2009.

37. Spivak GC. Pode o subalterno falar? Belo Horizonte: UFMG; 2014.

38. Pereira PPG. Queer decolonial: quando as teorias viajam. Contemporânea. 2015; 5(2):411-37.

39. Grossberg L. El corazón de los estudios culturales: contextualidad, construccionismo y complejidad. Tabula rasa [Internet]. 2009.

40. Quijano A. Colonialidade do poder, eurocentrismo e América Latina. In: CLACSO CL de CS, editor. A colonialidade do saber: eurocentrismo e ciências sociais Perspectivas latino-americanas [Internet]. Buenos Aires: CLACSO, Consejo Latinoamericano de Ciencias Sociales; 2005. p. 117-42.

41. Tiburi M. Lugar de fala e lugar de dor. Revista CULT [Internet]. 2017. Disponível em: <https://revistacult.uol. com.br/home/lugar-de-fala-e-etico-politica-da-luta/ > .

42. Leite Junior J. Nossos corpos também mudam: a invenção das categorias "travesti" e "transexual" no discurso científico. São Paulo: Annablume - FAPESP; 2011. 
43. Silva TT. Documentos de identidade: uma introdução às teorias do currículo. São Paulo - SP: Autêntica; 2016.

44. Freire P. Pedagogia da esperança: um reencontro com a pedagogia do oprimido. 21st ed. São Paulo - SP: Editora Paz e Terra; 2014

45. Freire P, Freire AMA, Oliveira WF. Pedagogia da solidariedade. 3rd ed. Rio de Janeiro - RJ / São Paulo - SP: Paz e Terra; 2018.

\section{AGRADECIMENTOS}

Agradeço à parceria do Programa de Pós Graduação em Saúde Coletiva da Universidade Estadual de Campinas (Unicamp) com o Department of Communication da University of Massachusetts (Umass) - Amherst/USA que potencializou a condução desta pesquisa. Agradeço, ainda, ao apoio enquanto bolsista do Programa de Doutorado Sanduíche no Exterior (PDSE), edital número 47/2017, processo número $88881.188456 / 2018-01$, visto que o presente trabalho foi realizado com o apoio da Coordenação de Aperfeiçoamento de Pessoal de Nível Superior - Brasil (CAPES) - Código de Financiamento 001.

\section{CONTRIBUIÇÃO DOS AUTORES}

Todos os autores participaram de todas as fases da elaboração deste manuscrito.

\section{CONFLITO DE INTERESSES}

Os autores declaram não haver conflitos de interesse.

\section{ENDEREÇO PARA CORRESPONDÊNCIA:}

Gustavo Antonio Raimondi

Av. Pará, 1720, Bloco 2U, sala 8 - bairro Umuarama CEP: 38400-902

Uberlândia, Minas Gerais - Brasil

E-mail: gustavo_raimondi@ufu.br 